\title{
Surto de dermatofilose em bezerros Nelore criados extensivamente em Goiás
}

\author{
Dermatophilosis Outbreak in Nelore Calves Raised Extensively in Goiás, Midwestern Brazil \\ Antônio Carlos Lopes Câmara', Ana Bárbara Rocha Silva', Márcio Botelho de Castro², \\ Anahí Souza Silva ${ }^{2}$, Simone Perecmanis ${ }^{3} \&$ José Renato Junqueira Borges'
}

Background: Dermatophilosis is an infectious-contagious disease of acute, subacute or chronic evolution caused by the etiologic agent Dermatophilus congolensis, and presents as hyperplastic or exudative dermatitis with crusty and scaly skin eruptions. Although it is a disease with important economic impact on Brazilian beef cattle, the reports of outbreaks in zebu cattle are restricted to the states of São Paulo and Mato Grosso do Sul. The present paper aimed to report the epidemiological, clinical, laboratorial and pathological findings of a dermatophilosis outbreak in Nelore calves raised extensively in Goiás, Midwestern Brazil.

Case: An outbreak of skin lesions in Nelore calves occurred on a farm located in Cocalzinho de Goiás, Goiás, Midwestern Brazil. Fifty one (25.5\%) of the 200 calves from 3-11-months-old presented cutaneous lesions. Forty nine of the calves were still suckling and two were weaned recently, and the most affected calves were offspring's of cows with the lowest body condition score. Three severely affected calves were clinically examined presenting regular body condition score, pale pink ocular mucosa, fever $\left(39.2-40.3^{\circ} \mathrm{C}\right.$ ), tachycardia (80-100 beats per minute), tachypnea (48-56 breaths per minute) and moderate presence of ticks. Skin inspection revealed crusty, elevated, non-pruritic lesions of grayish color that easily detached from the skin exposing a humid and hemorrhagic superficial lesion with pus. Lesions were widespread on the body with predominance on the face, ears, neck and dorsal region. Hematological findings of these calves presented leukocytosis $(16,083 \pm 1,910 / \mu \mathrm{L})$ by netrophilia $(11,121 \pm 2,349 / \mu \mathrm{L})$ and hyperfibrinogenemia $(966.6 \pm 208.16 \mathrm{mg} / \mathrm{dL})$. Biochemical alterations consisted of hypoproteinemia $(6.5 \pm 0.5 \mathrm{~g} / \mathrm{dL})$ and a slight increase in GGT activity in two calves (28 and 19 U/L, respectively). Skin lesions samples were stained by Giemsa and demonstrated filaments presenting characteristic "train tracks" pattern, formed by parallel chains of cocci. Microscopic findings consisted of suppurative superficial dermatitis associated with intralesional bacteria. Histological sections stained by Gram revealed typical branched filamentous structures formed by multiple rows of Gram positive spherical cocci. Initially, treatment consisted in improve the herd body condition score and ticks control. Calves were treated for dermatophilosis with streptomycin $\left(25 \mathrm{mg} \cdot \mathrm{kg}^{-1}\right.$, s.i.d., intramuscularly [IM], four days) and chlorhexidine diglylate $2 \%$ baths with manual crusts removal. Due to relapse in most calves caused by sub dosages by the owner, long-acting oxytetracycline ( $20 \mathrm{mg} . \mathrm{kg}^{-1}, \mathrm{q} 48 \mathrm{~h}$, IM, three doses) and stable disinfection was recommended. One year after this outbreak, the owner stated that there were no new cases on the farm.

Discussion: Definitive diagnosis of dermatophilosis in the calves of this report was conducted by the association of epidemiological, clinical, cytological and histological findings. In the present report, predisposing factors such as low body condition score due to food shortage, micro injuries on the skin caused by ticks infestation and mechanical trauma by Brachiaria brizantha, and high temperatures, possibly acted synergistically causing this outbreak. Dermatophilosis treatment with long-acting oxytetracycline associated with topical treatment and environment disinfection allowed clinical cure and prevention of new cases in this farm. Long-acting oxytetracycline presents good results in the treatment of natural cases of dermatophilosis, reaching cure rates varying from 71.4 to $100 \%$. Outbreaks of dermatophilosis in Nelore calves in Goiás may cause significant losses in beef cattle productivity and measures of control and prophylaxis should be considered for prevention.

Keywords: bacterial diseases, Dermatophilus congolensis, Nelore calves, skin lesions.

Descritores: Dermatophilus congolensis, doenças bacterianas, lesões de pele, bezerros Nelore. 


\section{INTRODUÇÃO}

A dermatofilose é uma enfermidade infectocontagiosa, de evolução aguda, subaguda ou crônica, causada pelo agente etiológico Dermatophilus congolensis, e se apresenta em forma de dermatite hiperplásica ou exsudativa com erupções cutâneas crostosas e escamosas $[2,3,9,10]$. A bactéria encontra-se presente na pele de animais assintomáticos e é incapaz de causar a doença na pele íntegra, mas age como agente oportunista mediante condições predisponentes $[2,5,13]$. O caráter zoonótico é de relevância médica considerando os relatos em humanos $[1,4]$.

Também conhecida como "estreptotricose cutânea dos bovinos", é considerada uma doença de importante impacto econômico na bovinocultura de corte brasileira [8]. Apesar disso, os relatos de surtos em zebuínos restringem-se aos Estados de São Paulo [6] e Mato Grosso do Sul [3,8]. Assim, o presente trabalho objetivou relatar os achados epidemiológicos, clínicos, laboratoriais e patológicos de um surto de dermatofilose em bezerros Nelore criados extensivamente em Goiás, Centro-Oeste do Brasil.

\section{CASOS}

As informações relatadas foram obtidas durante visita a uma propriedade de criação de bovinos, localizada no município de Cocalzinho de Goiás, Goiás. O rebanho era composto por 851 bovinos da raça Nelore criados extensivamente em pasto de Brachiaria brizantha cv. Marandu (braquiarão) e Andropogon sp. Os bovinos eram submetidos a vacinação periódica contra Febre Aftosa, Clostridioses e Raiva; além de vermifugação semestral com ivermectina $1 \%$. Na anamnese, o proprietário e tratadores relataram que no ano anterior, 36 bezerros exibiram lesões crostosas disseminadas, com morte de três animais por complicações associadas, como miíases e perda de peso progressiva. Os demais bezerros acometidos foram encaminhados para abate, sem nenhum atendimento veterinário. $\mathrm{Na}$ mesma propriedade no ano seguinte, em um lote de 200 bezerros com idade entre 3 a 11 meses, 51 (25,5\%) animais apresentaram lesões cutâneas semelhantes a do lote anterior, com os primeiros casos surgindo a partir de janeiro de 2016. Diante deste surto, o proprietário, por conta própria, iniciou tratamento com associação de penicilinas $(10 \mathrm{~mL}$, via intramuscular [IM], dose única). Devido ao insucesso no tratamento, solicitou visita clínica à propriedade pela equipe do Hospital
Escola de Grandes Animais da Universidade de Brasília em maio de 2016.

Três bezerros severamente afetados foram submetidos ao exame clínico, apresentavam-se em estação, comportamento alerta, escore corporal regular, mucosas oculares rosa-pálidas, febre $\left(39,2-40,3^{\circ} \mathrm{C}\right)$, taquicardia ( $80-100$ batimentos por min), taquipnéia (48-56 movimentos respiratórios por minuto) e presença moderada de carrapatos. A inspeção da pele dos animais revelou lesões crostosas, elevadas, não-pruriginosas, de coloração acinzentada, que, quando submetidas à tração ocorria o desprendimento das crostas e exposição de uma lesão superficial úmida e hemorrágica com pouco pus. Observou-se grande quantidade de crostas disseminadas, principalmente na face, orelhas, pescoço e região dorsal (Figura 1A-D). Dos 51 bezerros acometidos, 49 ainda eram lactentes e dois desmamados recentemente, sendo que os mais severamente afetados eram produtos de vacas com os escores corporais mais baixos. Nenhum dos bovinos adultos apresentavam lesões cutâneas semelhantes.

Amostras sanguíneas dos três bezerros foram colhidas através de venipunção jugular em tubo a vácuo com e sem anticoagulante EDTA $10 \%$ para realização do hemograma e dosagens bioquímicas (aspartato aminotransferase [AST], gamaglutamil transferase [GGT] e proteínas totais). As principais alterações laboratoriais nos três animais foram leucocitose com neutrofilia, hiperfibrinogenemia, hipoproteinemia e discreto aumento da GGT em dois bezerros (Tabela 1). Os demais parâmetros encontravam-se dentro dos limites fisiológicos para bovinos [7,14].

Amostras das lesões de pele e pelos obtidas por meio de raspado cutâneo para pesquisa de ectoparasi-

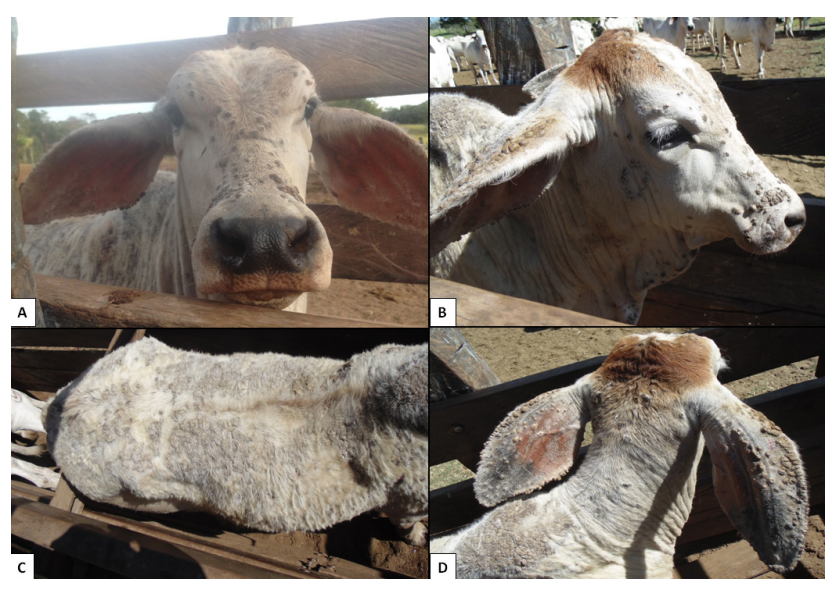

Figura 1. A,B,C,D- Bezerros da raça Nelore com lesões crostosas, elevadas, não-pruriginosas e de coloração acinzentada, com maior intensidade na face, orelhas e região dorsal. 
Tabela 1. Valores hematológicos e bioquímicos em três casos de dermatofilose em bezerros Nelore criados extensivamente.

\begin{tabular}{|c|c|c|c|c|c|}
\hline Parâmetro & Caso 1 & Caso 2 & Caso 3 & $\mathrm{X} \pm \mathrm{SD}$ & Valores de referência* \\
\hline Hematócrito (\%) & 36 & 38 & 47 & $40,3 \pm 5,85$ & $24-46$ \\
\hline 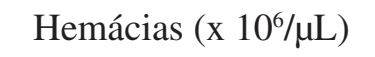 & 11,12 & 11,32 & 7,32 & $9,9 \pm 2,25$ & $5-10$ \\
\hline Hemoglobina $(\mathrm{g} / \mathrm{dL})$ & 10,7 & 10,8 & 13,3 & $11,6 \pm 1,47$ & $8-15$ \\
\hline $\mathrm{VCM}^{\mathrm{a}}(\mathrm{fL})$ & 32,3 & 33,5 & 64,2 & $43,3 \pm 18,08$ & $40-60$ \\
\hline $\operatorname{PPT}^{\mathrm{b}}(\mathrm{g} / \mathrm{dL})$ & 6,6 & 6 & 7 & $6,5 \pm 0,5$ & $7,0-8,5$ \\
\hline $\mathrm{FP}^{\mathrm{c}}(\mathrm{mg} / \mathrm{dL})$ & 1.200 & 800 & 900 & $966,6 \pm 208,16$ & $300-700$ \\
\hline Leucócitos Totais $(/ \mu \mathrm{L})$ & 18.100 & 14.300 & 15.850 & $16.083 \pm 1.910$ & $4.000-12.000$ \\
\hline Neutrófilos $(/ \mu \mathrm{L})$ & 13.213\# & 8.580 & 11.571 & $11.121 \pm 2.349$ & $600-4.000$ \\
\hline Linfócitos $(/ \mu \mathrm{L})$ & 3.801 & 4.433 & 3.012 & $3.748 \pm 711$ & $2.500-7.500$ \\
\hline Monócitos $(/ \mu \mathrm{L})$ & 1.086 & 1.287 & 1.110 & $1.161 \pm 109$ & $25-840$ \\
\hline Bastonetes $(/ \mu \mathrm{L})$ & - & - & 159 & $159 \pm 0$ & - \\
\hline $\mathrm{GGT}^{\mathrm{d}}(\mathrm{U} / \mathrm{L})$ & 28 & 19 & 11 & $19,3 \pm 8,5$ & $6,1-17,4$ \\
\hline $\operatorname{AST}^{\mathrm{e}}(\mathrm{U} / \mathrm{L})$ & 32 & 30 & 24 & $28,7 \pm 4,16$ & $20-34$ \\
\hline
\end{tabular}

avolume corpuscular médio; ${ }^{\text {b }}$ roteína plasmática total; ' fibrinogênio plasmático; dgama-glutamil transferase; easpartato aminotransferase; "Presença de neutrófilos tóxicos. "Kaneko et al. [7] \& Wood \& Quiroz-Rocha [14].

tas e exame citológico, não evidenciaram a presença de estruturas fúngicas ou ectoparasitas. A observação microscópica das amostras citológicas, corados pelo corante Giemsa, demonstrou grande número de organismos sob a forma de estruturas filamentosas, por vezes ramificadas, de coloração basofílica, misturadas por entre células epiteliais escamosas superficiais, detritos e material queratinizado. Em grande ampliação, foi observado que os filamentos apresentavam o padrão característico em "trilho de trem", formado por cadeias paralelas de estruturas cocóides (Figura 2).

Obteve-se biópsias cutâneas dos três bezerro com auxílio de punch de $8 \mathrm{~mm}$, que foram encaminhadas para processamento histológico. Os achados microscópicos consistiram de lesão inflamatória na derme superficial perivascular composta por moderada quantidade de neutrófilos e macrófagos, moderada espongiose, acantose e hiperqueratose paraqueratótica da epiderme e formação moderada de crosta serocelular superficial (Figura 3A). Secções histológicas coradas pela técnica de Gram evidenciaram na superfície epidérmica, associadas às lamelas córneas, estruturas filamentosas ramificadas típicas formadas por múltiplas fileiras de cocos esféricos Gram positivos (Figura 3B). Assim, concluiu-se o diagnóstico de dermatite superficial supurativa crostosa associada a estruturas bacterianas intralesionais, características da infecção por Dermatophilus congolensis.
O surto investigado ocorreu em período de estiagem anormal na região, associado a escassez de pastagens, moderada infestação parasitária por carrapatos e escore corporal baixo das vacas lactantes e bezerros. Diante deste quadro, preconizou-se a suplementação proteico-energética e administração de antiparasitário (Dectomax ${ }^{\circledR}{ }^{1}$, doramectina: 0,2 mg. $\mathrm{kg}^{-1}$, via subcutânea). O tratamento de dermatofilose consistiu da aplicação parenteral de estreptomicina (Estreptomax ${ }^{\circledR 2}: 25$ mg. $\mathrm{kg}^{-1}$, s.i.d., [IM], 4 dias) [8] e do uso tópico de digluconato de clorexidina $2 \%$ (Riohex $2 \%{ }^{3}$ ) com retirada manual das crostas, em

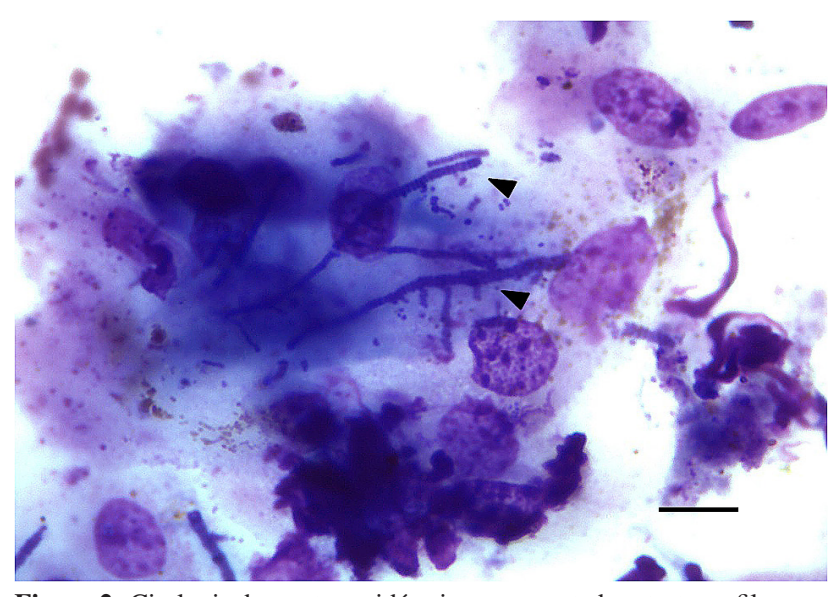

Figura 2. Citologia de crostas epidérmicas apresentado estruturas filamentosas ramificadas com múltiplas fileiras de coccus, com típica aparência de "trilho de trem" (cabeça de seta), da bactéria Dermatophilus congolensis na superfície dos queratinócitos [Giemsa. Barra $=10 \mu \mathrm{m}$ ]. 


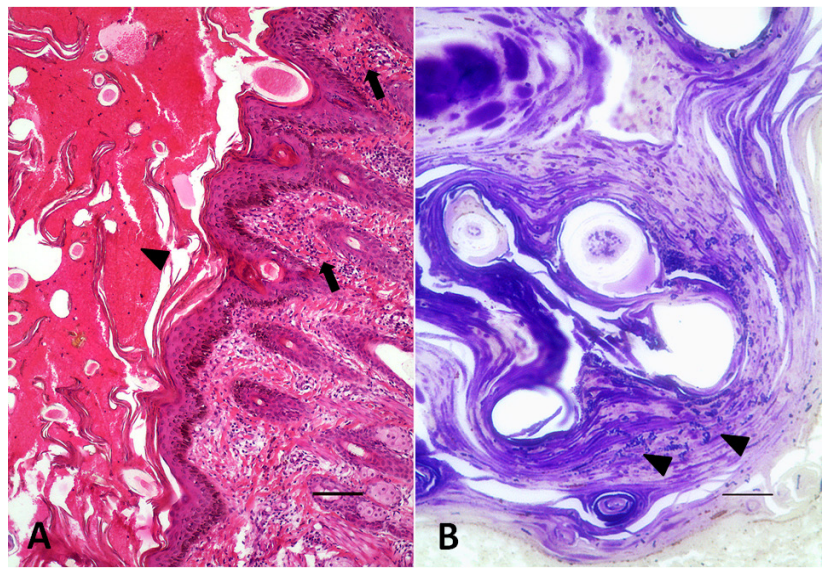

Figura 3. A- Dermatite superficial perivascular moderada (setas), acantose e abundante formação de crosta serocelular superficial (cabeça de seta) $[$ H\&E. Barra $=100 \mu \mathrm{m}]$. B- Bactérias cocóides Gram positivas dispostas em filamentos (cabeça de seta) por entre lamelas córneas ao redor de folículos pilosos [Gram. Barra $=40 \mu \mathrm{m}$ ].

dias alternados, totalizando três banhos. Associado a isso, orientou-se limpeza das instalações e uso de vassoura de fogo. Após o tratamento, o proprietário relatou a melhora significativa da condição clínica dos bezerros. Entretanto, após dois meses, houve recidiva do quadro dermatológico na maioria dos animais. Em nova visita clínica, os tratadores reportaram a aplicação de subdoses do antibiótico e e limpeza das instalações negligenciada. Assim, instituiu-se novo tratamento com oxitetraciclina de longa ação (Terramicina LA ${ }^{4}: 20$ mg.kg-1, q48 h, IM, 3 doses) e orientou-se novamente os banhos, retirada manual das crostas, queima de todo o material biológico obtido e desinfecção das instalações. Enfim, as orientações foram corretamente seguidas, com cura clínica de todos os bezerros acometidos. Após um ano do surto, o proprietário relatou que não houve novos casos da enfermidade.

\section{DISCUSSÃO}

Diversos fatores considerados estressantes, incluindo desmama, carência alimentar e traumatismos, associados a umidade e temperaturas elevadas, promovem o desequilíbrio das barreiras superficiais de defesa imunológica e inespecíficas da pele, com perda de sua integridade, e favorecem a invasão da pele por zoósporos de D. congolensis, [5,8,10,13]. No presente relato, o somatório de fatores predisponentes, como carência alimentar (evidenciado pelo baixo escore corporal), micro lesões da pele (devido a infestação por ectoparasitas e pastejo em $B$. brizantha) e elevadas temperaturas; possivelmente atuaram sinergicamente desencadeando o surto. A infestação por carrapatos, chuvas intensas e vegetação grosseira são considerados importantes fatores na patogênese da doença [3]. A infestação da pele por ectoparasitas parece estar relacionada à imunossupressão do hospedeiro, mais do que pela transmissão biológica ou mecânica da infecção $[2,3]$.

Os achados clínicos, citológicos e histológicos descritos são semelhantes a relatos anteriores $[1,3,5,6,13]$. As lesões crostosas que caracterizam clinicamente a enfermidade, resultam dos ciclos de invasão bacteriana, inflamação e regeneração da epiderme; responsáveis pela formação das crostas pustulares multilaminadas $[5,10]$. As alterações clínicas sistêmicas como febre, taquicardia e taquipnéia apresentadas pelos bezerros poderiam estar relacionadas diretamente à produção excessiva de mediadores químicos resultantes do extenso processo inflamatório na pele desencadeado pela infecção por $D$. congolensis [9]. Esse mesmo mecanismo também pode justificar as alterações hematológicas como leucocitose e hiperfibrinogenemia, em decorrência da infecção bacteriana e inflamação cutânea [14].

O uso parenteral de penicilina procaína (20.000-70.000 UI.kg ${ }^{-1}$ ) ou estreptomicina (25-70 $\mathrm{mg} \cdot \mathrm{kg}^{-1}$ ) é considerado tratamento de eleição para dermatofilose $[8,10,13]$. Entretanto, acredita-se que o tratamento prévio com subdosagens pelo proprietário, associado a deficiente retirada das crostas e desinfecção das instalações, propiciaram condições para a manutenção do agente e reinfecção do rebanho, uma vez que o microrganismo pode persistir em crostas secas por mais de 42 meses no ambiente [9]. Diante da recidiva, a utilização de oxitetraciclina de longa ação, associada ao correto tratamento tópico e desinfecção das instalações, permitiu a cura clínica e prevenção de novos casos nesta propriedade. $\mathrm{O}$ uso deste antibiótico na posologia instituída apresenta bons resultados no tratamento de casos naturais de dermatofilose, alcançando índices de cura variando de 71,4 a $100 \%[1,3,6]$.

O diagnóstico presuntivo da enfermidade é realizado pela epidemiologia, sinais clínicos e visualização da bactéria cocóide Gram positiva com formação de arranjos filamentosos em esfregaços corados pelo Gram ou Giemsa, enquanto o diagnóstico definitivo é firmado mediante isolamento, caracterização da bactéria em crostas e biópsia da lesão [4,8,10,13]. Os achados citológicos em esfregaços de lesões cutâneas 
corados pelo método Gram ou Giemsa são considerados base para o diagnóstico, e permitem a rápida confirmação da infecção por $D$. congolensis $[5,9]$. No presente estudo, o diagnóstico definitivo foi realizado através da associação entre os dados epidemiológicos, achados clínicos, citológicos e histológicos. Neste surto, o diagnóstico preciso da doença permitiu o tratamento correto e a instituição de medidas de controle eficazes, minimizando as perdas causadas pela dermatofilose.

Em bezerros Nelore criados extensivamente, o principal diagnóstico diferencial é a fotossensibilização hepatógena por ingestão de Brachiaria spp. [3,11]. Além de dermatite com edema, espessamento cutâneo e exsudato amarelado; os sinais clínicos podem incluir icterícia, depressão, hiporexia, edema de orelhas, urina escura e morte [11]. Em bovinos, GGT, AST, fosfatase alcalina e sorbitol desidrogenase são as mais úteis na identificação de doença hepática crônica [12], sendo o discreto aumento da GGT nos bezerros deste relato incompatível com o quadro de hepatopatia pela planta $[11,12]$.
$\mathrm{O}$ alto índice de morbidade de $25 \%$ nos bezerros Nelore desta propriedade em Goiás reforça a importância econômica que essa enfermidade pode assumir na bovinocultura deste estado, assim como comprovado no Mato Grosso do Sul [3,8]. Reitera-se que surtos de dermatofilose podem causar perdas relevantes na produtividade dos rebanhos bovinos no Centro-Oeste, sendo importante a conscientização dos médicos veterinários de campo para a correta instrução dos produtores e técnicos sobre as medidas de controle e profilaxia.

\section{MANUFACTURERS}

'Zoetis Indústria de Produtos Veterinários Ltda. Chapecó, SC, Brazil.

${ }^{2}$ Ourofino Saúde Animal Ltda. Cravinhos, SP, Brazil.

${ }^{3}$ Rioquímica S/A. São José do Rio Preto, SP, Brazil.

${ }^{4}$ Zoetis Indústria de Produtos Veterinários Ltda. Chapecó, SC, Brazil.

Declaration of interest. The authors report no conflicts of interest. The authors alone are responsible for the content and writing of the paper.

\section{REFERENCES}

1 Awad W.S., Nadra-Elwgoud M.I.A. \& El-Sayed A.A. 2008. Diagnosis and treatment of bovine, ovine and equine dermatophilosis. Journal of Applied Sciences Research. 4(4): 367-374.

2 Ambrose N., Lloyd D. \& Maillard J.C. 1999. Immune responses to Dermatophilus congolensis infections. Parasitology Today. 15(7): 295-300.

3 Bacha F.B., Faccin T.C., Lima S.C., Leal C.R.B. \& Lemos R.A.A. 2014. Dermatofilose em bezerros da raça Nelore no Mato Grosso do Sul. Semina: Ciências Agrárias. 35(4): 1947-1954.

4 Burd E.M., Juzych L.A., Rudrik J.T. \& Habib F. 2007. Pustular dermatitis caused by Dermatophilus congolensis. Journal of Clinical Microbiology. 45(5): 1655-1658.

5 Castelo Branco R.L., Drummond V.O., Andrade H.H., Lacerda R.M.L.G., Marques A.D.S.S., Souza Mello M.R., Oliveira V.H.S., Perecmanis S. \& Borges J.R.J. 2012. Dermatofilose em ovinos da raça Santa Inês no Distrito Federal. Arquivo Brasileiro de Medicina Veterinária e Zootecnia. 64(5): 1184-1187.

6 Cunha P.H.J., Siqueira A.K., Oliveira Filho J.P., Badial P.R., Oliveira A.P., Listoni F.J.P., Ribeiro M.G. \& Borges A.S. 2010. Dermatofilose em bovinos criados em regime de confinamento. Veterinária e Zootecnia. 17(2): 224-228.

7 Kaneko J.J., Harvey J.W. \& Bruss M.L. 1997. Clinical biochemistry of domestic animals. 5th edn. San Diego: Academic Press, 932p. 8 Lemos R.A.A. \& Silveira A.C. 2008. Dermatofilose. In: Lemos R.A.A. \& Leal C.R.B. (Eds). Doenças de impacto econômico em bovinos de corte. Campo Grande: Ed. UFMS, pp.349-354.

9 Olinda R.G., Câmara A.C.L. \& Feijó F.M.C. 2009. Primeiro relato de dermatofilose generalizada em equino no Rio Grande do Norte. Acta Veterinaria Brasilica. 3(4): 187-192.

10 Pereira D.B. \& Meireles M.C.A. 2007. Dermatofilose. In: Riet-Correa F., Schild A.L., Lemos R.A.A. \& Borges J.R.J. (Eds). Doenças de ruminantes e equídeos. v.1. 3.ed. Santa Maria: Pallotti, pp.280-286.

11 Riet-Correa B., Castro M.B., Lemos R.A.A., Riet-Correa G., Mustafa V.S. \& Riet-Correa F. 2011. Brachiaria spp. poisoning of ruminants in Brazil. Pesquisa Veterinária Brasileira. 31(3): 183-192.

12 Santos J.C.A., Riet-Correa F., Simões S.V.D. \& Barros C.S.L. 2008. Patogênese, sinais clínicos e patologia das doenças causadas por plantas hepatotóxicas em ruminantes e equinos no Brasil. Pesquisa Veterinária Brasileira. 28(1): 1-14.

13 Scott D.W. 1988. Large Animal Dermatology. Philadelphia: Saunders, pp.136-146.

14 Wood D. \& Quiroz-Rocha G.F. 2010. Normal hematology of cattle. In: Weiss D.J. \& Wardrop K.J. (Eds). Schalm's Veterinary Hematology. 6th edn. Ames: Wiley-Blackwell, pp.829-837.

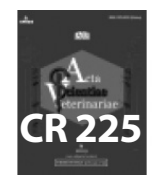

